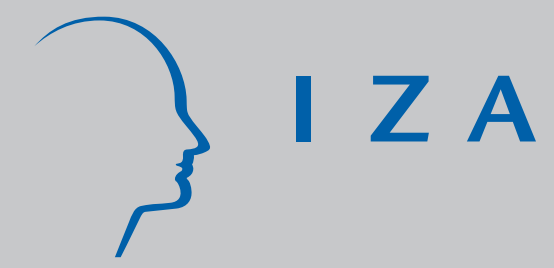

IZA DP No. 554

Employment Protection, Product Market Competition and Growth

Winfried Koeniger

August 2002 


\title{
Employment Protection, Product Market Competition and Growth
}

\author{
Winfried Koeniger
}

IZA Bonn

\author{
Discussion Paper No. 554 \\ August 2002 \\ substantially revised version available as: \\ IZA Discussion Paper No. 888 (October 2003)
}

IZA
P.O. Box 7240
53072 Bonn
Germany

Phone: +49-228-3894-0

Fax: +49-228-3894-180

E-mail: iza@iza.org

Any opinions expressed here are those of the author(s) and not those of the institute. Research disseminated by IZA may include views on policy, but the institute itself takes no institutional policy positions.

The Institute for the Study of Labor (IZA) in Bonn is a local and virtual international research center and a place of communication between science, politics and business. IZA is an independent nonprofit company supported by Deutsche Post World Net. The center is associated with the University of Bonn and offers a stimulating research environment through its research networks, research support, and visitors and doctoral programs. IZA engages in (i) original and internationally competitive research in all fields of labor economics, (ii) development of policy concepts, and (iii) dissemination of research results and concepts to the interested public.

IZA Discussion Papers often represent preliminary work and are circulated to encourage discussion. Citation of such a paper should account for its provisional character. A revised version may be available directly from the author. 
IZA Discussion Paper No. 554

August 2002

\section{ABSTRACT \\ Employment Protection, Product Market Competition and Growth ${ }^{*}$}

It is commonly argued that labor market institutions such as employment protection worsen an economy's performance and particularly so, if product markets become more competitive. Empirical evidence, however, has difficulties to detect a robust negative correlation between employment protection and growth. We show in a model with step-by-step innovations that whether employment protection decreases incentives to innovate and thus productivity growth depends on the degree of product market competition. For reasonable parameter values product market deregulation fosters growth substantially more in the flexible than in the constrained economy.

JEL Classification: J65, L1, O31

Keywords: $\quad$ step-by-step innovations, firing cost, Schumpeterian growth

Winfried Koeniger

IZA

P.O. Box 7240

53072 Bonn

Germany

Tel.: +49-228-3894-512

Fax: +49-228-3894-510

Email: koeniger@iza.org

\footnotetext{
* I thank Anders Sørensen for a very helpful discussion of the paper; and Stephan Kohns, Gilles SaintPaul and participants of the IZA workshop "European Integration and Labor Market Performance", 2002, for comments and suggestions.
} 


\section{Introduction}

Interactions between labor and product markets have received considerable attention in recent years. On the one hand it is crucial to analyze such interactions and their effect on economic performance in order to understand why both types of regulation vary substantially across OECD countries and tend to be positively correlated (see, e.g., Nicoletti et al. (2001)). On the other hand the interactions are of particular interest for Europe where product markets have become increasingly competitive in the process of European integration and labor markets are quite regulated. The question we want to address in this paper is whether labor market regulations such as employment protection are necessarily bad for economic growth and how the relationship between the two depends on product market competition.

In perfect and complete markets the answer to this question is clear: employment protection is bad for growth. In the models of Hopenhayn and Rogerson (1993) and Bertola (1994) employment protection hampers efficient reallocation of factors across sectors. Bertola (1994) shows how this affects the investment behavior of forward-looking firms and exerts a negative effect on growth. Empirical evidence, however, has difficulties to detect a robust negative effect of employment protection on growth in the data. Nickell and Layard (1999) find that employment protection

and productivity growth are positively correlated in OECD countries in the period 1976-92. The OECD (2001) and Bassanini and Ernst (2002) find an ambiguous relationship between employment protection and R\&D for the years 1993-97. Bentolila and Dolado (1994), p. 69, report that temporary employment and productivity growth are negatively correlated in Spain after controlling for worker characteristics.

In this paper we explain this empirical evidence by relaxing the assumption of perfect competition. We show that the degree of product market competition is crucial for the relationship between employment protection and growth. We build on the model of Aghion et al. (2001) (see also Aghion and Howitt (1998), ch. 7.4). Aghion et al. (2001) use the concept of step-by-step innovations to generate a positive effect of competition on innovation and thus growth, which in the standard 
Schumpeterian model is always negative. Step-by-step innovations mean that a technology laggard first has to catch up before he can become a technology leader. An important feature of this model is that introducing some competition makes profits positively depend on the relative position on the technology frontier. This implies that competition can foster innovation although the absolute value of the firm falls as competition increases. Intuitively, firms escape competition by innovating. Building on the model of Aghion et al. (2001) ensures that our model is consistent with the empirical evidence that product market competition is positively related to productivity growth (see Nickell (1999) and Bassanini and Ernst (2002)), although the relationship might become negative for high levels of competition (see Aghion et al. (2002)).

The contribution of this paper is to add employment protection to the model of Aghion et al. (2001). We show that step-by-step innovations do not only change the results of a standard Schumpeterian model for the effect of product market competition on growth, but also for the effect of labor market institutions on growth. In the standard Schumpeterian model flexibility is always good for growth (see, e.g., Saint-Paul (1996), p. 173). In a model with step-by-step innovations instead, we show that growth does not necessarily have to be lower in economies with employment protection if product markets are not competitive. For a given level of employment in the economy with employment protection, low levels of competition imply relatively more employment than in the flexible economy. This depresses the marginal revenue product of labor used in production and makes it more attractive to use workers for R\&D. Analogously, if product markets are very competitive, employment and growth are higher in the more flexible economy. Moreover, we show that firing costs can foster innovation if firms face the risk to close down. Since firms incur firing costs if they close down and technologically advanced firms have to close down with a smaller probability, there is a dynamic incentive to innovate. This is an additional channel that can induce growth in the constrained economy to be higher than in the flexible economy especially if product markets are not very competitive.

Let us now further relate this paper to the existing literature. Some recent papers have modeled the labor market in an aggregated way to study interactions with product markets. E.g., Blanchard 
and Giavazzi (2001) analyze the effects of bargaining power in the labor market and monopoly power in product markets on the movements of the labor share. Bertola and Boeri (2001) analyze the interactions of labor and product markets by focusing on the labor demand elasticity and the markup over wages. In this paper we focus on the interaction of product market competition with one type of labor market regulation, i.e., employment protection.

As mentioned above employment protection is bad for growth if markets are perfect and complete. The following papers relax this assumption to show that employment protection can increase productivity. As we will point out, however, all these paper are not consistent with the empirical finding that competition can increase growth. In the paper of Levine and Tyson (1990) higher job security increases employee participation and thus productivity where employers do not offer job security on their own initiative because of adverse selection. Offering more security compared to other firms would result in low-effort job applicants (see Levine (1991)). A formal exposition how employment protection can increase worker's productivity is provided by Fella (2000). He shows in a model with search frictions that severance payments increase the firm's willingness to invest in worker's general training. ${ }^{1}$ This is because separation is less likely to occur in which case the firm looses all of its investment since the human capital is embodied in the worker. In Fella's model large severance payments or consensual layoff agreements will induce firms to bargain efficiently over the joint payoff from separation. Another explanation is put forward by Saint-Paul (2002). In his model production of goods is relatively less risky at late stages of the product cycle. Saint-Paul shows that firing costs decrease R\&D activity for innovating new goods, the "primary" innovation, whereas they increase R\&D for imitation of mature goods, the "secondary" innovation.

However, all these explanations are at odds with empirical evidence that product market competition is positively related to productivity growth. Increases in the variability of product demand and resulting layoffs will decrease employee participation according to Levine and Tyson (1990), so that an increase in product market competition lowers productivity. In the model of Fella (2000) the joint surplus of the match decreases if product markets are more competitive. As turnover rises

\footnotetext{
${ }^{1}$ In a similar modeling framework Belot et al. (2002) show that firing costs let workers exert more effort.
} 
in the labor market, firm's investment in general training falls. Finally, in the model of Saint-Paul (2002) higher turnover in the labor market resulting from product market competition or higher production risk decreases $\mathrm{R} \& \mathrm{D}$ for "primary" innovation in favor of $\mathrm{R} \& \mathrm{D}$ for "secondary" innovation. Our model instead is consistent with both pieces of empirical evidence, the positive correlation between product market competition and growth on the one hand and the non necessarily negative correlation between employment protection and growth on the other hand.

The rest of the paper is structured as follows. In Section 2 we present the model. In Section 3 we derive the main result that the effect of employment protection on growth crucially depends on the degree of product market competition. In Section 4 we show that the risk to close down resulting from adverse shocks creates additional incentives to innovate. We conclude in Section 5.

\section{The Model}

The basic model of the flexible economy without industry shocks is as in Aghion et al. (2001). Hence, we refer to their paper for further discussion of the major assumptions and more detailed derivations.

The economy has a continuum of production sectors and a continuum of consumers.

Consumers Households with infinite horizon have the preferences

$$
U(c, l)=\int_{0}^{\infty} e^{-r t}\left[\int_{0}^{1} \ln c_{i}(t) d i-l(t)\right] d t
$$

where $c_{i}$ denotes consumption of good $i, r$ is the market interest rate which equals the discount rate and $l$ denotes the labor supplied by each household. The preferences imply infinitely elastic labor supply. ${ }^{2}$ Furthermore, log-utility implies that a fixed amount of expenditure is spent on each good where expenditure is normalized to $1 .^{3}$ From the household's maximization problem it then follows that the wage is 1 , too.

\footnotetext{
${ }^{2}$ As pointed out by Aghion et al. (1997) inelastic labor supply will lower the effects of product market competition on innovations because wages rise as employment does which lowers the rents obtained by innovating.

${ }^{3}$ Note that strictly speaking we need to define consumer utility as $\ln \left(c_{i}+\underline{c}\right), \underline{c}>0$, for utility to be well defined if
} 
Producers There are barriers to entry and markets are characterized by a duopoly. Hence, rents occur in this market although the production function has constant returns. This is done to avoid that unit costs depend on the quantities produced. With fixed costs the most efficient way to produce would be achieved with one firm only. However, more competition lowers research effort in the classic Schumpeterian monopoly model. Hence, such a framework would not be consistent with the empirical evidence that product market competition increases productivity.

Industry output is characterized by

$$
x_{i}=g_{i}\left(x_{a}, x_{b}\right)=\left(x_{a}^{\alpha_{i}}+x_{b}^{\alpha_{i}}\right)^{\frac{1}{\alpha_{i}}}
$$

where the two firms in each sector produce output $x_{a}$ and $x_{b}$, respectively. Although $\alpha_{i}$ is really a taste parameter, it relates to standard measures of competition. E.g., a higher $\alpha_{i}$ implies a higher elasticity of demand and less market power. Note that in the limit case of $\alpha=1$ there is Bertrand competition since we let firms compete in prices (see below). ${ }^{4}$ We assume for simplicity that competition is the same across industries, i.e., $\alpha=\alpha_{i} \in(0 ; 1)$. Then the problem structure is symmetric for all industries so that we drop the industry index $i$ in the rest of the paper.

Households maximize $g\left(x_{a}, x_{b}\right)$ subject to $p_{a} x_{a}+p_{b} x_{b}=1$ in order to determine how much of the good is bought from firm $a$ and $b$. This results in

$$
x_{a}=\frac{p_{a}^{\frac{1}{\alpha-1}}}{p_{a}^{\frac{\alpha}{\alpha-1}}+p_{b}^{\frac{\alpha}{\alpha-1}}}
$$

and

$$
x_{b}=\frac{p_{b}^{\frac{1}{\alpha-1}}}{p_{a}^{\frac{\alpha}{\alpha-1}}+p_{b}^{\frac{\alpha}{\alpha-1}}},
$$

where $p_{a}$ denotes the price of the good produced by firm $a$. The elasticity of demand (defined as a positive number) corresponding to the demand functions derived above is

$$
\eta_{j}=\frac{1-\alpha \lambda_{j}}{1-\alpha}
$$

the whole industry $i$ closes down (see below). Alternatively, we could restrict the support of the industry shocks to prevent this from happening.

${ }^{4}$ For firms competing in quantities and a comparison of Bertrand and Cournot equilibria see Aghion et al. (1997). 
for each firm where $j=a, b$. The revenue, $\lambda \equiv p x$, can be written as

$$
\lambda_{j}=\frac{p_{j}^{\frac{\alpha}{\alpha-1}}}{p_{a}^{\frac{\alpha}{\alpha-1}}+p_{b}^{\frac{\alpha}{\alpha-1}}},
$$

where $\lambda_{a}+\lambda_{b}=1$.

Let us now assume that each good is produced with labor. The production function is assumed to have constant returns. Labor is fully elastically supplied. Firms take the wage $w$ as given. This implies that employment protection is not neutral for firms in our model (see, e.g., Lazear (1990) or Alvarez and Veracierto (2001)). Because of the normalization assumption that expenditure is 1, $w=1$. The cost of every production unit is $\rho_{j}$ which varies between firms according to how many units of labor are necessary for production.

\subsection{Flexible Economy}

We now determine profits and R\&D efforts first in the flexible economy and subsequently in the constrained economy.

Profits Given the assumptions made above, in equilibrium the profit-maximizing price of firm $j$ in the flexible economy is

$$
p_{j}=\frac{\eta_{j}}{\eta_{j}-1} \rho_{j}=\frac{1-\alpha \lambda_{j}}{\alpha\left(1-\lambda_{j}\right)} \rho_{j} .
$$

It follows that total profits in equilibrium are

$$
\pi_{j}=\frac{\lambda_{j}}{\eta_{j}}=\frac{\lambda_{j}(1-\alpha)}{1-\alpha \lambda_{j}}
$$

Equations $(3)^{\sim}(5)$ can be used to solve for unique equilibrium prices, revenues and profits. As is shown in Aghion et al. (2001), for given $\alpha$ equilibrium profits of firm $j$ are determined by the relative cost $z \equiv \frac{\rho_{j}}{\rho_{-j}}$ since the demand for the good of industry $i$ is unit-elastic. If both firms advance on the technology frontier so that $z$ remains unchanged, prices fall and demand rises by the same proportion so that revenues remain unchanged. Thus, labor-saving technological progress does not decrease employment in production. The amount of labor saved per unit of production is absorbed by expanding production. 
R\&D Each sector is assumed to be a duopoly also in R\&D. The R\&D effort is assumed to depend on the current state of technology which implies that we search for symmetric stationary equilibria in Markov strategies. We do derive results for the case of very large innovations in order to convey the main message as simple as possible. The results are more general, however, as shown by Aghion et al. (2001) because smaller innovations increase the incentive to innovate resulting from more competitive product markets. With small innovations the appropriability effect of standard Schumpeterian models vanishes. Because of the appropriability effect, competition is bad for growth in standard Schumpeterian models since competition decreases the rents derived from innovation.

In the case of very large innovations there are three states of the firm, $\{1,0,-1\}$, which denote the technology leader being one step ahead, neck-and-neck firms and the technology laggard, respectively. Step-by-step innovations mean that a technology laggard first has to catch up before he can become a technology leader. Employing $\frac{\beta q^{2}}{2}$ units of labor, $\beta>0$, a firm moves one step forward on the technology frontier with the endogenous Poisson hazard rate $q$. Because of very large innovations the technology leader does not exert any research effort, i.e., $q_{1}=0$. The technological follower catches up with the leader at rate $q_{-1}$. If this happens, firms are neck-and-neck. Neck-and-neck competition is defined as $z=1$ where $z \equiv \frac{\rho_{j}}{\rho_{-j}}, j=a, b$. I.e., both firms have the same input requirement and thus the same unit cost. Firms in neck-and-neck competition exert research effort $q_{0}$ which is then also the endogenous Poisson hazard rate of each firm to become a technology leader. If a firm advances one step, its input requirement for production falls by the factor $\gamma^{-1}, \gamma>1$. Hence, the relative cost of the technological leader being one step ahead is $z=\gamma^{-1}$.

Using subscripts again to denote the relative technology level, the expected present value of the firm $V$ in the three states satisfies the following equations for small time intervals:

$$
\begin{gathered}
r V_{1}=\pi_{1}+q_{-1}\left(V_{0}-V_{1}\right), \\
r V_{0}=\pi_{0}+q_{0}\left(V_{1}-V_{0}\right)+\stackrel{\text { rival }^{\prime} s \& D}{\stackrel{q_{0}}{q_{0}}}\left(V_{-1}-V_{0}\right)-\frac{\beta\left(q_{0}\right)^{2}}{2}
\end{gathered}
$$


and

$$
r V_{-1}=\pi_{-1}+q_{-1}\left(V_{0}-V_{-1}\right)-\frac{\beta\left(q_{-1}\right)^{2}}{2}
$$

The rate of return from performing $\mathrm{R} \& \mathrm{D}$ has to equal the rate of return available in the market, $r$. E.g., in equation (8) for technology laggards, the returns of performing $\mathrm{R} \& \mathrm{D}$ contain profit flows $\pi_{-1}$ and the change of the firm's value of moving one step ahead on the technology frontier, $V_{0}-V_{-1}$, which happens with probability $q_{-1}$. Moreover, there is a flow cost for the R\&D effort of $\frac{\beta\left(q_{-1}\right)^{2}}{2}$.

The resulting optimal research efforts $q_{0}$ and $q_{-1}$ are found maximizing the respective right-hand side of equations $(6)^{\sim}(8)$ so that we get:

$$
\begin{gathered}
q_{1}=0 \\
q_{0}=\frac{V_{1}-V_{0}}{\beta}
\end{gathered}
$$

and

$$
q_{-1}=\frac{V_{0}-V_{-1}}{\beta}
$$

Subtracting equation (7) from equation (6), and equation (8) from equation (7), using equations (10) and (11) yields

$$
\frac{1}{2} q_{0}^{2}+r q_{0}=\frac{\pi_{1}-\pi_{0}}{\beta}
$$

and

$$
\frac{1}{2} q_{-1}^{2}+r q_{-1}=\frac{\pi_{0}-\pi_{-1}}{\beta}+\frac{1}{2} q_{0}^{2}-q_{0} q_{-1}
$$

which determine $q_{0}$ and $q_{-1}$ as a function of relative profits $\pi_{1}-\pi_{0}$ and $\pi_{0}-\pi_{-1}$. 
In fact, equations (12) and (13) imply

$$
q_{0}=-r+\sqrt{r^{2}+\frac{2\left(\pi_{1}-\pi_{0}\right)}{\beta}}
$$

and

$$
q_{-1}=-\left(r+q_{0}\right)+\sqrt{\left(r+q_{0}\right)^{2}+q_{0}^{2}+\frac{2\left(\pi_{0}-\pi_{-1}\right)}{\beta}} .
$$

We know from Aghion et al. (2001), Proposition 1, that $\pi_{1}>\pi_{0}>\pi_{-1}$ and $\pi_{1}-\pi_{0}>\pi_{0}-\pi_{-1}$ so that research efforts are highest if firms are neck-and-neck. Note again that with step-by-step innovations research efforts only depend on relative profits. This is why competition can increase growth although the absolute value of the firm falls.

Aghion et al. (2001) derive the steady state distribution of firms in each state and show that for the case of very large innovations the growth rate is

$$
g=\frac{2 q_{0} q_{-1}}{2 q_{0}+q_{-1}} \ln \gamma
$$

It follows that the growth rate is higher if firms put more effort in $\mathrm{R} \& \mathrm{D}$, i.e., if $q_{0}$ or $q_{-1}$ is larger.

\subsection{Constrained Economy}

Assume that in the constrained economy firing and hiring costs are such that workers are never hired or fired when firms change their relative position on the technology frontier. I.e., we assume that the shadow value of labor $J_{k}$ is always greater or equal to the firing cost per worker $F$ and smaller than the hiring cost per worker $H$. For example the condition for the technology laggard reads $-F \leq J_{-1} \leq H$. Assuming that no worker is fired or hired in the economy with employment protection is extreme. However, it allows us to make the point as simple as possible. This is particularly so below, when we introduce stochastic shocks into the model.

Given that workers are never fired, firms employ the same amount of labor $L$ independent of their position on the technology frontier. Hence, instead of choosing the price as in the flexible 
economy, in the constrained economy firms decide how many of the workers are used for production, $L^{p}$, and how many for $\mathrm{R} \& \mathrm{D}, L^{r}$. It is important to note that for the results obtained below we need that the input used in production can also be used for $R \& D$. In this case, labor which is slack in the production sector of the constrained economy will be employed for R\&D so that the marginal revenue product of labor is the same for both activities. The arbitrage equation is

$$
\frac{\partial \lambda_{k}\left(L_{k}^{p}\right)}{\partial L_{k}^{p}}=\frac{1}{\sqrt{2 \beta L_{k}^{r}}}\left(V_{k+1}-V_{k}\right)
$$

The marginal revenue product of labor in production on the left-hand side has to equal the expected marginal benefit of labor used for $\mathrm{R} \& \mathrm{D}$ on the right-hand side where $k \in\{1,0,-1\}$. The expression for the marginal productivity of labor used for $R \& D$ is derived by noting that the benefit of $R \& D$ is $q_{k}\left(V_{k+1}-V_{k}\right)$ for which $L_{k}^{r}=\frac{\beta\left(q_{k}\right)^{2}}{2}$ units of labor are necessary. Hence,

$$
q_{k}=\sqrt{\frac{2 L_{k}^{r}}{\beta}}
$$

and

$$
\frac{\partial q_{k}}{\partial L_{k}^{r}}=\frac{1}{\sqrt{2 \beta L_{k}^{r}}}
$$

which implies the expression on the right-hand side of equation (17). Equation (17) will determine $L^{p}$ and $L^{r}$. In order to see this we still need to show how prices, revenues and profits are determined.

Profits For a given $L^{p}$ firms $j=a, b$ produce

$$
x_{j}=\left(\rho_{j}\right)^{-1} L_{j}^{p}
$$

units of output. Using equations (1) and (2), market clearing implies that

$$
\frac{p_{j}}{p_{-j}}=\left(\frac{x_{j}}{x_{-j}}\right)^{\alpha-1}=\left(z L_{-j}^{p} / L_{j}^{p}\right)^{1-\alpha} .
$$

Equation (3) and (19) then imply that firm's revenues depend on the relative position on the technology frontier as in the flexible economy and the relative labor input used in production, i.e.,

$$
\lambda_{j}=\left(\left(\frac{p_{-j}}{p_{j}}\right)^{\frac{\alpha}{\alpha-1}}+1\right)^{-1}=\left(\left(z L_{-j}^{p} / L_{j}^{p}\right)^{\alpha}+1\right)^{-1} .
$$


Prices are determined as

$$
p_{j}=\frac{\lambda_{j}}{x_{j}}=\frac{\rho_{j}}{L_{j}^{p}\left(\left(z L_{-j}^{p} / L_{j}^{p}\right)^{\alpha}+1\right)}
$$

so that profits are

$$
\pi_{j}=\left(p_{j}-\rho_{j}\right) x_{j}=\lambda_{j}-L_{j}^{p}
$$

Equations $(20)^{\sim}(22)$ express revenues, prices and profits as a function of $L^{p}$.

R\&D In the flexible economy R\&D efforts are such that the marginal benefit of performing R\&D equals the marginal cost. This is no longer the case in the constrained economy where the amount of total labor employed is fixed and $L^{r}$ is chosen so that the productivity of labor is equal in production and R\&D. Calculating the marginal revenue product of labor in production using equation (20) and

$$
L^{r}=L-L^{p}
$$

equation (17) becomes

$$
\frac{\alpha\left(z L_{-j}^{p} / L_{j}^{p}\right)^{\alpha}}{L_{j}^{p}\left(\left(z L_{-j}^{p} / L_{j}^{p}\right)^{\alpha}+1\right)^{2}}=\frac{\left(V_{k+1}-V_{k}\right)}{\sqrt{2 \beta\left(L-L_{j}^{p}\right)}}
$$

which implicitly defines the optimal $L_{j}^{p}$ where $V\left(L^{p}\right)$. Denoting the marginal revenue product of labor in production on the left-hand side of equation (24) by $M R P L^{p}$, one can verify that

$$
\lim _{L^{p \rightarrow \infty}} M R P L^{p}=0
$$

and

$$
\lim _{L^{p} \rightarrow 0} M R P L^{p} \rightarrow \infty
$$

Instead the marginal benefit of $\mathrm{R} \& \mathrm{D}$ can be finite if $L^{r}=0$ and at the same time $V_{k+1}-V_{k}=0$. This is the case for $\alpha=0$, when the value of the firm is independent of its position on the technology 
frontier. Finally, note that for neck-and-neck firms

$$
M R P L^{p}=\frac{\alpha}{4 L_{0}^{p}}
$$

because $z=1$ and $L_{-j}^{p} / L_{j}^{p}=1$.

Once the amount of production workers $L_{k}^{p}$ is determined in equation $(24), \mathrm{R} \& \mathrm{D}$ effort $q_{k}$ follows from equations (23) and (18). The growth rate is determined as in the flexible economy (see equation (16)).

\section{Growth and Product Market Competition}

We now compare growth in the flexible and constrained economy as the degree of product market competition changes. We start by comparing the two special cases $\alpha=1$ and $\alpha=0$. In the flexible economy without competition, i.e., $\alpha=0$, the profit of firms is independent of the relative position on the technology frontier. Firms produce an infinitesimal amount for an infinitely high price so that profits are $1 / 2$ (see equations (3) and(5)). There is no innovation so that the growth rate is 0 . In the constrained economy without competition equation (20) shows that if $\alpha=0$ revenues do not depend on the relative position on the technology frontier. $\mathrm{R} \& \mathrm{D}$ is useless and $M R P L^{p}=0$ for an infinitesimal $L^{p}$. Hence, labor is slack and $q_{k}=0$. Hence, for $\alpha=0$, growth is zero in both the flexible and constrained economy.

In the flexible economy firms engage in monopolistic competition if $\alpha=1$. Because of Bertrand competition only one firm remains in the market and obtains all the profits because of its superior technology. In the constrained economy instead there will still be two firms producing if $\alpha=1$ and the quantity constraint imposed by employment protection is binding. Hence, if $\alpha=1 \mathrm{R} \& \mathrm{D}$ and growth will be smaller in the constrained than in the flexible economy.

We solve the model numerically for intermediate values of $\alpha$ using the parameter values reported in Table 1. 
Table 1: Parameter Values

\begin{tabular}{cc}
\hline \hline$\beta=1$ & $\gamma=1.2$ \\
$r=.03$ & $L=.15$ \\
\hline
\end{tabular}

We set $\beta=1$ so that the cost of innovation is $\frac{q^{2}}{2}$ which scales growth rates to reasonable values given the other parameters. The interest rate $r$ is set to .03 which is within the interval of values commonly used. Since we consider very large innovations we parametrize $\gamma$ as 1.2 which means that a technology laggard needs $20 \%$ more inputs to produce the same output as the technology leader. We let $L=.15$ for firms in the constrained economy. This is roughly the optimal amount of labor employed by the technology leader in the flexible economy if $\alpha=.5$, i.e., at medium competition levels.

We want to compare growth rates in the flexible and constrained economy as we decrease or increase product market competition starting from medium competition values. Since it is optimal for firms not to adjust employment $L$ because of high firing and hiring costs, the effects of changes of product market competition on growth rates have to be interpreted as short to medium run effects. This is particularly so because we do not include natural turnover resulting from quits of workers or exit and entry of firms. Results that are not reported show that if we calculate the optimal $L$ for every $\alpha$ in the constrained economy, $L$ positively depends on $\alpha$. Hence, the mechanism mentioned below is the stronger the longer it takes to adjust the amount of employed workers. For presentation purposes we consider the extreme case no adjustment at all. In the longer run natural turnover, i.e., exit or entry of firms or workers will tend to adjust $L$ even if firing costs are high. Note that in the standard Schumpeterian model such turnover is intrinsic in the creative destruction process whereas in the model with step-by-step innovations we consider this is not necessarily the case.

Figure 1 displays the growth rate in the flexible and constrained economy for the chosen parameter values for values of $\alpha \in(0 ; 1)$. Note that if $\alpha=0$, there is no growth in the flexible and constrained economy as mentioned above. Figure 1 illustrates the following: 


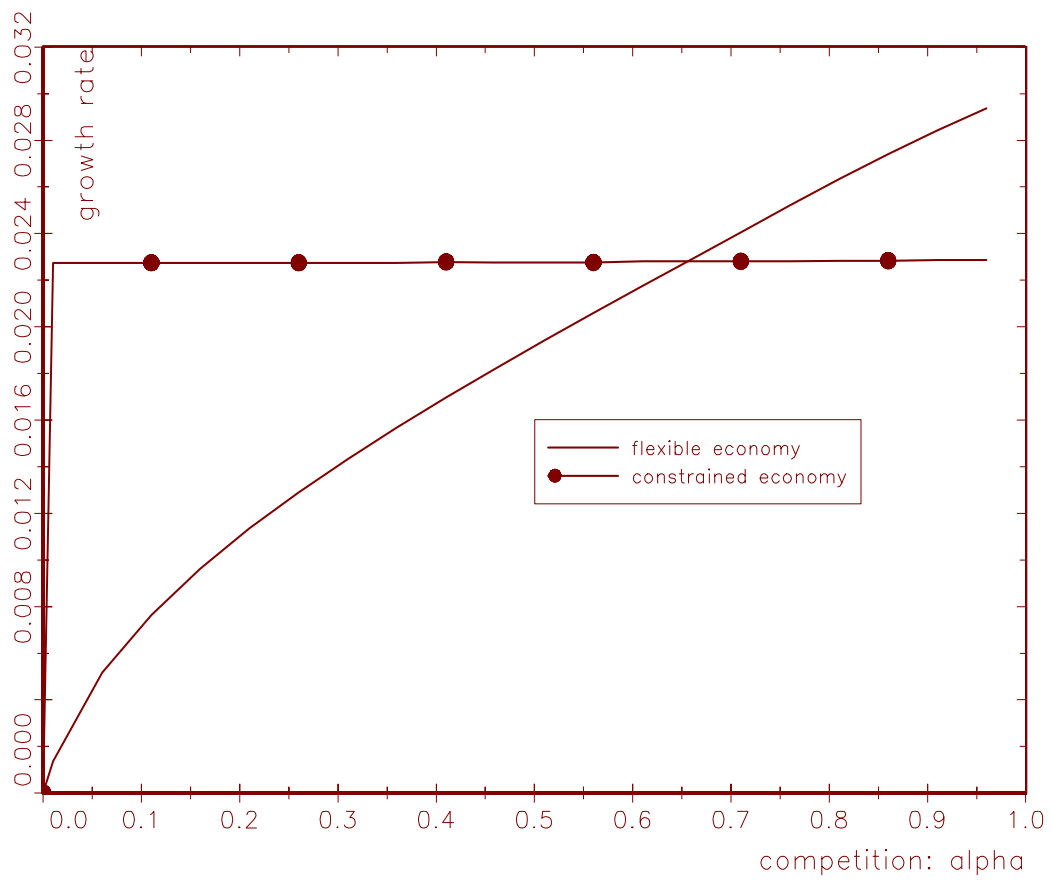

Figure 1: Employment protection and growth as a function of product market competition 
1. Whether employment protection is good or bad for growth depends on the degree of product market competition.

Let $\alpha^{*}$ denote the value of $\alpha$ at which growth in the flexible and constrained economy are equal. If the product market is not competitive enough, i.e., if $\alpha<\alpha^{*}$, growth is higher in the constrained economy. Depending on the parameter values, it is possible that we get corner solutions so that growth is always higher or equal in the flexible or in the constrained economy, respectively. The crucial parameter is $L$. If $\alpha \lll \alpha^{*}$, the amount of employed workers per firm $L$ is substantially larger in the constrained economy than in the flexible economy. Instead, if $\alpha \ggg \alpha^{*}$, the amount of workers per firm $L$ is substantially smaller than in the flexible economy. In the former case the firm will employ more workers in both production and R\&D so that the marginal benefit of both tasks is the same. This why growth rates are higher (smaller) in the constrained than in the flexible economy if $\alpha \lll \alpha^{*}\left(\alpha \ggg \alpha^{*}\right)$. Note that $\alpha^{*}$ is different from the value of $\alpha$ at which labor employed is the same in the flexible and constrained economy. This is because in the constrained economy R\&D and production are related through the arbitrage equation (24).

2. Unless $\alpha$ is close to 0 , product market competition fosters growth substantially more in the flexible economy.

Deregulation of product markets is relatively more beneficial for economies with flexible labor markets. In the model this results from the fact that in the constrained economy the marginal benefit of $\mathrm{R} \& \mathrm{D}$ is compared to the $M R P L^{p}$ whereas in the flexible economy it is compared to the marginal cost of R\&D. It is verified that

$$
\frac{\partial M R P L^{p}}{\partial \alpha}>0
$$

for the technology leader and neck-and-neck firms whereas

$$
\frac{\partial M R P L^{p}}{\partial \alpha}<0
$$

for technology laggards. The intuition is that the demand for the industry's good becomes more elastic as $\alpha$ increases which hurts the technology laggard who produces the good at higher 
cost than the technology leader. For neck-and-neck firms who are exactly alike, the intuition is like for a monopolist. Production increases as the mark-up falls resulting from the higher elasticity of demand. In the constrained economy this affects R\&D because of the arbitrage equation (24). Hence, as competition becomes more intense, $M R P L^{p}$ increases for neck-and-neck firms, but so does the marginal benefit of $\mathrm{R} \& \mathrm{D}$ because the technology leader becomes relatively better off. For the chosen parameter values it turns out that the overall effect on $R \& D$ is negative. For the technology laggard instead $M R P L^{p}$ decreases and the marginal benefit of $\mathrm{R} \& \mathrm{D}$ increases so that R\&D increases. The opposite effects for the laggard and neck-and-neck firm nearly offset each other so that the growth rate in the constrained economy is insensitive to changes in $\alpha$. Of course, in the region in which $\alpha$ is close to 0 , i.e., where $\mathrm{R} \& \mathrm{D}$ starts to be beneficial, labor is employed for $\mathrm{R} \& \mathrm{D}$ relatively more in the constrained economy since $M R P L^{p}$ is particularly low.

\section{The growth rate is highest in the flexible and competitive economy as long as $\alpha^{*}<1$.}

This holds as long as the quantity constraint implied by employment protection is binding (see the discussion of the case $\alpha=1$ above). This scenario is consistent with the higher growth rates in the UK or US, countries with competitive product markets and flexible labor markets, compared with the lower growth rates in continental Europe where labor markets are quite regulated.

Note that in our numerical example growth rates increase in the flexible economy as product markets become more competitive. In general, the relationship between growth rates and competition is non-linear as shown by Aghion et al. (2001). The main insights are robust, however, because the results for the limit cases $\alpha=0$ and $\alpha=1$ are unambiguous.

So far we have considered the stylized case in which firms never fire because of prohibitively high firing costs. We relax this assumption in the next section in which we introduce stochastic profit shocks. In this case we are able to show that there are additional incentives to innovate in the constrained economy in order to avoid firing costs. 


\section{Extension: Stochastic Profit Shocks}

To keep the model as simple as possible we assume that every industry is exposed to an i.i.d. exogenous profit shock $\varepsilon .^{5}$ This shock can be interpreted as an unexpected change of an industry's business conditions such as costs of law suits resulting from unforeseen consequences of new inventions or government subsidies for certain industries. We let this shock be uniformly distributed in the interval $[\underline{\varepsilon} ; \bar{\varepsilon}]$ normalizing the expected value to $E(\varepsilon)=0$ and denoting the cumulative distribution function with $F(\varepsilon)$. We let the support of the distribution be such that firms do close down their business should they be exposed to an adverse enough shock. The explicit condition will be mentioned below. Once a firm closes down a new firm takes its place in the market in the next period. ${ }^{6}$ This allows us to preserve the duopoly structure of the industries and simplifies the analysis considerably. ${ }^{7}$

If the realization of $\varepsilon$ is smaller than the critical value $\varepsilon_{k}$, workers are fired and firms incur total firing costs of size $s$. This critical value depends on the firms' position on the technology frontier. The technology leader will close down if $V_{1}^{E} \leq-s$, the neck-and-neck firm will do so if $V_{0}^{E} \leq-s$ and the technology laggard fires workers if $V_{-1}^{E} \leq-s$ where the superscript $E$ denotes the constrained economy with profit shocks. Since $V_{1}^{E}>V_{0}^{E}>V_{-1}^{E}$, it follows that $\varepsilon_{1}<\varepsilon_{0}<\varepsilon_{-1}<0$ (see equations $(31)^{\sim}(33)$ in the appendix for the implicit definitions of the $\varepsilon_{k}$ 's, $k \in\{1,0,-1\}$ ). Technologically more advanced firms close down if relatively more adverse shocks occur. Hence,

\footnotetext{
${ }^{5}$ The shock could also be firm specific without changing the results derived below. The model would need to be slightly adapted because then also technology laggards or neck-and-neck firms could become a monopolist for one period (see below).

${ }^{6}$ This is optimal for the firm as long as the value of being in the market exceeds the entry cost. One can think of the "new" firm as the firm that has closed down previously and takes up business again if business conditions are more favorable, i.e., if a larger $\varepsilon$ is realized. Since we look at the case of very large innovations so that the technology leader never innovates, we can neglect changes of the relative technology position while one firm is out of business.

${ }^{7}$ In this paper we are interested in the interactions between increases in competition within given industries and labor market institutions. Hence, we keep the industry structure constant. Letting the industry structure be endogenous is a challenging task for future research.
} 
the probability of closing down decreases as firms advance on the technology frontier: $F\left(\varepsilon \leq \varepsilon_{1}\right)<$ $F\left(\varepsilon \leq \varepsilon_{0}\right)<F\left(\varepsilon \leq \varepsilon_{-1}\right)$.

We continue to assume that firing costs are such that it is optimal for firms not to adjust their workforce as their relative technological position improves or deteriorates, but only if a negative enough profit shock occurs which forces a firm to close down. This assumption makes our model tractable because under this assumption all firms face the same cost $s$ when they close down and we do not have to consider the firm-specific workforce as an additional state variable.

Note that markets always clear in the economy because we consider an infinite number of industries. The law of large numbers implies that the same mass of firms closes down every period so that also the same number of workers is employed.

We model employment protection as a cost $s$ which is borne by the firm if it fires $L$ workers. Equations $(6)^{\sim}(8)$ then become

$$
\begin{gathered}
V_{1}^{E}=\int_{\underline{\varepsilon}}^{\bar{\varepsilon}} \max \left\{\frac{1}{r}\left[\pi_{1}^{E}+\varepsilon+\left(1-I_{\left\{\varepsilon_{1} \leq \varepsilon \leq \varepsilon_{-1}\right\}}\right) q_{-1}^{E}\left(V_{0}^{E}-V_{1}^{E}\right)+I_{\left\{\varepsilon_{1} \leq \varepsilon \leq \varepsilon_{-1}\right\}}\left(\pi_{m}-\pi_{1}^{E}\right)\right],-s\right\} d F(\varepsilon), \\
V_{0}^{E}=\int_{\underline{\varepsilon}}^{\bar{\varepsilon}} \max \left\{\frac{1}{r}\left[\pi_{0}^{E}+\varepsilon+q_{0}^{E}\left(V_{1}^{E}-V_{0}^{E}\right)+{\substack{\text { rival }^{\prime} s R \& D \\
\downarrow}}_{q_{0}^{E}}^{E}\left(V_{-1}-V_{0}\right)-\frac{\beta\left(q_{0}^{E}\right)^{2}}{2}\right],-s\right\} d F(\varepsilon)
\end{gathered}
$$

and

$$
V_{-1}^{E}=\int_{\underline{\varepsilon}}^{\bar{\varepsilon}} \max \left\{\frac{1}{r}\left[\pi_{-1}^{E}+\varepsilon+q_{-1}^{E}\left(V_{0}^{E}-V_{-1}^{E}\right)-\frac{\beta\left(q_{-1}^{E}\right)^{2}}{2}\right],-s\right\} d F(\varepsilon) .
$$

Profit flows $\pi_{k}^{E}, k \in\{1,0,-1\}$, are determined by equation (22). Moreover, note in equation (25) that the technology leader can become monopolist for a small time interval before a new firm enters. The indicator function $I_{\left\{\varepsilon_{1} \leq \varepsilon \leq \varepsilon_{-1}\right\}}$ is one if this event occurs, i.e., if $\varepsilon_{1} \leq \varepsilon \leq \varepsilon_{-1}$. The probability of this event is $F\left(\varepsilon_{1} \leq \varepsilon \leq \varepsilon_{-1}\right)$. In this case the industry shock is such that the 
technology leader continues to produce whereas the technology laggard closes down. The profits of the monopolist, $\pi_{m}$, are 1 in the flexible economy and $1-L$ in the constrained economy. In the flexible economy the monopolist charges an infinite price for an infinitesimal quantity and hence extracts all consumer expenditure (which we normalized to 1) without incurring costs. In the constrained economy the monopolist cannot shed labor and thus incurs the cost $w L$. Note that the monopolist technology leader remains leader with probability 1 since the laggard closes down. I.e., the term $q_{-1}^{E}\left(V_{0}^{E}-V_{1}^{E}\right)$ only matters if $\varepsilon \geq \varepsilon_{-1}$.

It is useful to rewrite equations $(25)^{\sim}(27)$ as

$$
\begin{aligned}
& V_{1}^{E}=F\left(\varepsilon \leq \varepsilon_{1}\right)(-s)+F\left(\varepsilon>\varepsilon_{1}\right) \bar{V}_{1}^{E}, \\
& V_{0}^{E}=F\left(\varepsilon \leq \varepsilon_{0}\right)(-s)+F\left(\varepsilon>\varepsilon_{0}\right) \bar{V}_{0}^{E}
\end{aligned}
$$

and

$$
V_{-1}^{E}=F\left(\varepsilon \leq \varepsilon_{-1}\right)(-s)+F\left(\varepsilon>\varepsilon_{-1}\right) \bar{V}_{-1}^{E},
$$

where $\bar{V}_{k}^{E}$ is the value of a firm conditional on survival, i.e., when $\varepsilon \geq \varepsilon_{k}$. For the technology laggard, e.g., this value reads

$$
\bar{V}_{-1}^{E} \equiv \frac{1}{r}\left[\pi_{-1}^{E}+\int_{\varepsilon-1}^{\bar{\varepsilon}} \varepsilon d F(\varepsilon)+q_{-1}^{E}\left(V_{0}^{E}-V_{-1}^{E}\right)-\frac{\beta\left(q_{-1}^{E}\right)^{2}}{2}\right] .
$$

Recall from equation (17) that the marginal benefit using labor for $\mathrm{R} \& \mathrm{D}$ is $\left(V_{k+1}^{E}-V_{k}^{E}\right) / \sqrt{2 \beta L^{r}}$. Since

$$
V_{k+1}^{E}-V_{k}^{E}=\left(F\left(\varepsilon \leq \varepsilon_{k}\right)-F\left(\varepsilon \leq \varepsilon_{k+1}\right)\right) s+F\left(\varepsilon>\varepsilon_{k+1}\right) \bar{V}_{k+1}^{E}-F\left(\varepsilon>\varepsilon_{k}\right) \bar{V}_{k}^{E}
$$

and because of the envelope theorem ${ }^{8}$

$$
\frac{\partial\left(V_{k+1}^{E}-V_{k}^{E}\right)}{\partial s}=F\left(\varepsilon \leq \varepsilon_{k}\right)-F\left(\varepsilon \leq \varepsilon_{k+1}\right)>0 .
$$

\footnotetext{
${ }^{8}$ The envelope theorem implies that $\varepsilon_{k}$ and $\bar{V}_{k}^{E}$ are optimized and thus do not change at the margin.
} 
Thus, an increase in the cost of shedding labor increases the marginal product of $\mathrm{R} \& \mathrm{D}$ and thus growth since technologically more advanced firms are less likely to close down. The size of the effect is larger the more the probability of costly firing decreases as firms advance on the technology frontier. We summarize:

Profit shocks increase growth in the economy with firing costs relative to the flexible economy for $\alpha>0$.

Product market competition amplifies this effect if relative profits rise (see Figure 1 above and Aghion et al. (2001) for a formal exposition). Equations $(25)^{\sim}(27)$ in the Appendix then imply that $\varepsilon_{k}-\varepsilon_{k+1}$ increases and so does $F\left(\varepsilon \leq \varepsilon_{k}\right)-F\left(\varepsilon \leq \varepsilon_{k+1}\right)$ so that the effect of firing cost on the marginal benefit of using labor for R\&D becomes relatively larger. However, as in the case without profit shocks relative profits, and thus R\&D and growth, increase less than in the flexible economy as competition becomes more intense. Hence, in terms of Figure 1, $\alpha^{*}$ increases and so does the region in which growth rates are higher in the constrained economy than in the flexible economy for given parameters. Note that with profit shocks growth can be higher in the constrained economy even if this is never the case without profit shocks. However, we have considered only marginal changes. If $s$ is so large that it is optimal for firms to close down, it is obvious that firing costs cannot increase growth.

Note that in the model we have taken the total number of workers $L$ as given since we have modeled exit and entry only very stylized in Section 4 and have abstracted from them entirely in Section 3. Alternatively, we could also determine the optimum $L^{*}$ a firm would employ if it decides to start production. In our model $L^{*}$ increases as competition increases, but it is unclear whether employment protection would induce more or less labor demand than in the flexible economy for the same reasons pointed out in standard labor demand models (see, e.g., the survey of Bertola $(1999))$. 


\section{Conclusions}

Our model shows that the relationship between employment protection and growth depends on the degree of product market competition. Employment protection is bad for growth if competition is intense, but not necessarily so if product markets are very regulated. Hence, in the light of our model it is not surprising that empirical studies get ambiguous results for the effect of employment protection on growth. Moreover, our model relates to the aggregate analysis of Bertola and Boeri (2001) in an interesting way. Bertola and Boeri show that in regulated labor markets product market competition is more likely to have positive employment effects the larger are the efficiency increases resulting from more intense product market competition. Our model points out that this is more likely if the economy is flexible.

However, our model is partial in an important respect. We do not explicitly analyze entry decisions of firms. In our model it is always optimal for firms to enter because markets are regulated which implies rents. In further research it would be interesting to endogenize the industry structure to jointly analyze the effect of employment protection on incumbents and entrants.

From a policy perspective our model can rationalize why product market and labor market regulations are highly positively correlated in OECD countries (see Nicoletti et al. (2001)). In our model economic performance is not necessarily adversely affected by employment protection if product markets are very regulated. In countries with competitive product markets instead, growth can increase substantially if labor markets are deregulated. If countries try to optimize economic performance, product and labor market regulations will be used complementary. Saint-Paul (2002) shows that political support for employment protection is indeed larger in economies in which growth is low. Countries that have other objectives than just economic performance, however, might find it optimal to use product and labor market regulation as substitutes (see, e.g., Agell (1999)). If markets are incomplete, insurance of risk-averse agents through employment protection can be optimal as economies become more open and competitive.

Finally, according to our numerical results, deregulating product markets increases growth only 
slightly in countries with employment protection whereas growth increases substantially in the flexible economy so that growth rates are highest in countries with deregulated product and labor markets. This is consistent with the higher growth rates in the UK or US compared with continental Europe.

\section{Appendix}

The critical values of the shocks at which firms close down follow from equations $(25)^{\sim}(27)$ :

$$
\begin{gathered}
\varepsilon_{1}+r s+\pi_{m}=0 \\
\varepsilon_{0}+r s+\pi_{0}+q_{0}^{E}\left(V_{1}-V_{0}\right)+\stackrel{\substack{r^{i v a l}{ }^{\prime} s R \& D \\
q_{0}^{E}}}{E}\left(V_{-1}-V_{0}\right)-\frac{\beta}{2}\left(q_{0}^{E}\right)^{2}=0, \\
\varepsilon_{-1}+r s+\pi_{-1}+q_{-1}^{E}\left(V_{0}-V_{-1}\right)-\frac{\beta}{2}\left(q_{-1}^{E}\right)^{2}=0 .
\end{gathered}
$$

Equation (31) follows because the technology leader only closes down if the technology laggard is already out of business. 


\section{References}

[1] Agell, Jonas (1999): "On the Benefits from Rigid Labour Markets: Norms, Market Failures, and Social Insurance", Economic Journal, vol. 109, F143-64.

[2] Aghion, Philippe and Peter Howitt (1998), Endogenous Growth Theory, MIT Press, Cambridge.

[3] Aghion, Philippe, Christopher Harris, and John Vickers (1997): "Competition and Growth with Step-by-Step Innovation: An Example", European Economic Review, Papers and Proceedings, vol. 41, 771-782.

[4] Aghion, Philippe, Christopher Harris, Peter Howitt and John Vickers (2001): "Competition, Imitation and Growth with Step-by-Step Innovation", Review of Economic Studies, vol. 68, 467-92.

[5] Aghion, Philippe, Nicholas Bloom, Richard Blundell, Rachel Griffith and Peter Howitt (2002): "Competition and Innovation: An Inverted U Relationship", University College London, mimeo.

[6] Alvarez, Fernando and Marcelo Veracierto (2001): "Severance Payments in an Economy with Frictions", Journal of Monetary Economics, vol. 47, 477-98.

[7] Bassanini, Andrea and Ekkehard Ernst (2002): "Labor Market Institutions, Product Market Regulation, and Innovation: Cross-Country Evidence", OECD Economics Department Working Papers No. 316.

[8] Belot, Michèle, Jan Boone and Jan C. van Ours (2002): "Welfare Effects of Employment Protection", CEPR Discussion Paper No. 3396.

[9] Bentolila, Samuel and Juan J. Dolado (1994): "Labour Flexibility and Wages: Lessons from Spain", Economic Policy, Issue 18, 53-99. 
[10] Bertola, Giuseppe (1994): "Flexibility, Investment, and Growth", Journal of Monetary Economics, vol. 34, 215-38.

[11] Bertola, Giuseppe (1999): "Microeconomic Perspectives on Aggregate Labor Markets", in: Handbook of Labor Economics, Ashenfelter, Orley and David Card (eds.), vol. 3C, ch. 45, North Holland, Amsterdam.

[12] Bertola, Giuseppe and Tito Boeri (2001): "EMU Labor Markets Two Years On: Microeconomic Tensions and Institutional Evolution", in: EMU and Economic Policy in Europe: The Challenge of the Early Years, Buti, Marco and André Sapir (eds.), Edward Elgar, Aldershot.

[13] Blanchard, Olivier and Francesco Giavazzi (2001): "Macroeconomic Effects of Regulation and Deregulation in Goods and Labor Markets", NBER Working Paper No. 8120.

[14] Fella, Giulio (2000): "Investment in General Training with Consensual Layoffs", Queen Mary, University of London, mimeo.

[15] Hopenhayn, Hugo and Richard Rogerson (1993): "Job Turnover and Policy Evaluation: A General Equilibrium Analysis", Journal of Political Economy, vol. 101, 915-38.

[16] Lazear, Edward P. (1990): "Job Security Provisions and Employment", Quarterly Journal of Economics, vol. 105, 609-726.

[17] Levine, David I. (1991): "Just Cause Employment Policies in the Presence of Worker Adverse Selection", Journal of Labor Economics, vol. 9, 294-305.

[18] Levine, David I. and Laura D'A.Tyson (1990): “Participation, Productivity, and the Firm's Environment", in: Paying for Productivity, Alan Blinder (ed.), The Brookings Institution, Washington, D.C.

[19] Nickell, Stephen (1999): "Product Markets and Labor Markets", Labor Economics, vol. 6, $1-20$. 
[20] Nickell, Stephen and Richard Layard (1999): " Labor Market Institutions and Economic Performance", in: Handbook of Labor Economics, Ashenfelter, Orley and David Card (eds.), vol. 3C, ch. 46, North Holland, Amsterdam.

[21] Nicoletti, Giuseppe, Robert C.G. Haffner, Stephen Nickell, Stefano Scarpetta and Gylfi Zoega (2001): "European Integration, Liberalization and Labor Market Performance", in: Welfare and Employment in a United Europe, Bertola, Giuseppe, Tito Boeri and Giuseppe Nicoletti (eds.), MIT Press, Cambridge, 147-235.

[22] OECD (2001): "The Cross-Market Effects of Product and Labour Market Policies", in: Economic Outlook, vol. 2001/2002, No. 70, ch. 6, Paris.

[23] Saint-Paul, Gilles (1996): Dual Labor Markets: A Macroeconomic Perspective, MIT Press, Cambridge.

[24] Saint-Paul, Gilles (2002): "Employment Protection, International Specialization, and Innovation", European Economic Review, forthcoming.

[25] Saint-Paul, Gilles (2002): "The Political Economy of Employment Protection", Journal of Political Economy, vol. 110, 672-704. 


\section{IZA Discussion Papers}

No. Author(s)

539

Y.-F. Chen

D. Snower

G. Zoega

540

G. S. Epstein

A. Kunze

M. E. Ward

541

B. Cockx

M. Dejemeppe

542

M. Frölich

543

544

545

546
A. M. Stiglbauer
F. Stahl
R. Winter-Ebmer
J. Zweimüller

G. S. Epstein

I. N. Gang

548

M. Frölich

E. Wasmer

D. Clark

E. Epstein

I. N Gang

$$
\text { R. Fahr }
$$

U. Sunde

S. Machin

P. A. Puhani

W. Koeniger
Title

Area

Date

Labour-Market Institutions and Macroeconomic

3

Shocks

High Skilled Migration and the Exertion of Effort

$08 / 02$ by the Local Population

Do the Higher Educated Unemployed Crowd Out 2 the Lower Educated Ones in a Competition for Jobs

Programme Evaluation with Multiple Treatments

Wages, Productivity, and Work Intensity in the

5 Great Depression

Disentangling the Minimum Wage Puzzle: An

3

Analysis of Worker Accessions and Separations

The Role of Background Factors for Reading Literacy: Straight National Scores in the PISA 2000 Study

Job Creation and Job Destruction in a Regulated 2 Labor Market: The Case of Austria

Government and Cities: Contests and the

3

$08 / 02$

Decentralization of Decision Making

What is the Value of Knowing the Propensity

Score for Estimating Average Treatment Effects?

Interpreting Europe and US Labor Markets

Differences: The Specificity of Human Capital Investments

The Impact of Local Labour Market Conditions on Participation in Further Education in England

Herd Effects or Migration Networks?

The Location Choice of Mexican Immigrants in the U.S.

Estimations of Occupational and Regional

Matching Efficiencies Using Stochastic

Production Frontier Models

Subject of Degree and the Gender Wage

2

$08 / 02$

Differential Evidence from the UK and Germany

Employment Protection, Product Market

$08 / 02$ 